\title{
Comparative Study on Training Mode of Engineering Specialty Undergraduate between U.S and China
}

\author{
Wenbo Jiang \\ School of Electrical Engineering and Electronic Information, Xihua University, Chengdu 610039, \\ China \\ jiangwenbo@mail.xhu.edu.cn
}

\begin{abstract}
To improve the declining training quality of undergraduate student caused by increasing enrollment number year by year, a comparative study on training mode of engineering specialty undergraduate student between American and Chinese universities was proposed in this paper. We selected University of Michigan (U.S) and Xihua University (China) as a main sample, and other several universities were also considered in our study. Some detailed comparisons were conducted from the aspects of training objective, training plan and curriculum system, training quality evaluation system, respectively. Finally, some reform measures and operable proposals on training mode of engineering specialty undergraduate student are discussed, which is beneficial for undergraduate education in our country.
\end{abstract}

Keywords: Training mode; Engineering specialty undergraduate student; Operable proposal.

\section{Introduction}

In 1999, the Ministry of Education of China began to increase the enrollment number of undergraduate student, and the number was increasing year by year from 1999 to 2012. The number of fresh graduates from college or university was also increasing year by year. Fig.1 shows the growth trend of the number of fresh graduates from college or university, where the horizontal coordinate is time (unit: year), and the longitudinal coordinate is the number of fresh graduates from college or university (unit: ten thousands). As shown in Fig.1, one can see that the number reached 7.49 million in 2015, which attained the historic peak level.

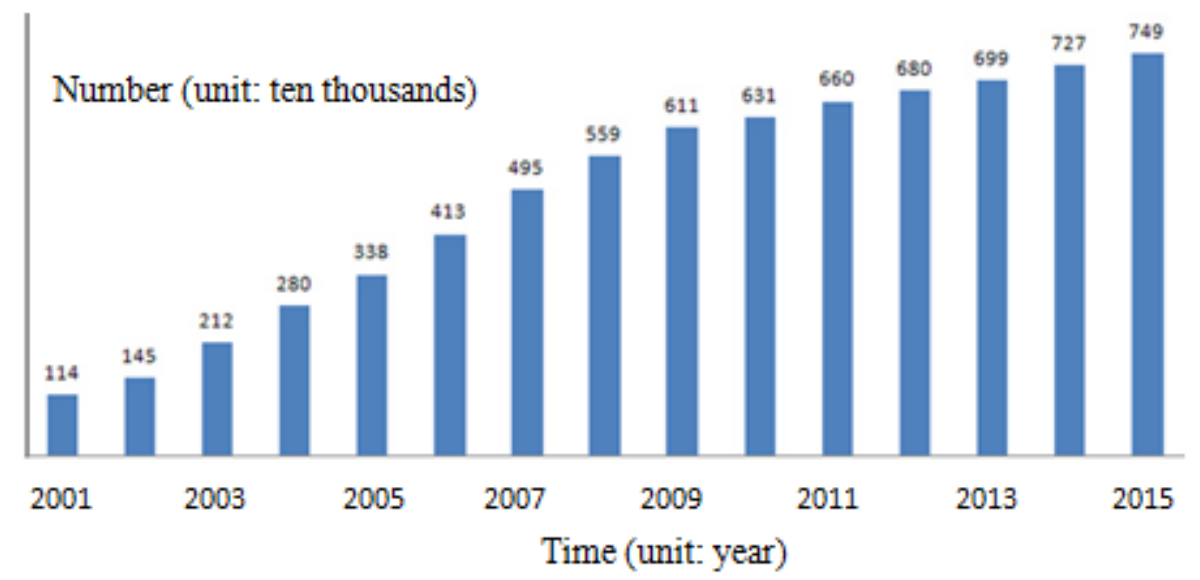

Fig. 1 The growth trend of the number of fresh graduates from college or university

However, research results show that the increase of the enrollment number of undergraduate student led to the declining training quality and employment quality. To find a sustainable and effective solution of this problem, government and universities have taken some positive and effective measures, such as Excellent Engineers Education Training Plan, Engineering Education Professional Certification, etc.

In this paper, I will compare the training modes between American and Chinese universities from the aspects of training objective, training plan and curriculum system, training quality evaluation system, etc. These comparisons are mainly based on the author's oversea study experience (09/2014-09/2015, University of Michigan, Ann Arbor, US), and the training model of other similar 
universities is also considered. Finally, some reform measures and operable proposals are discussed, which based on the current situation of training mode of engineering specialty undergraduate student in our country.

\section{Comparative Analysis of Training Mode}

\subsection{Training Objective.}

U.S: Undergraduate education is the basic education for people, but not for an intensive training for a specific occupation. Compared with the vocational education, undergraduate education emphasizes the cultivation of "people", and students need to study art, history, philosophy, humanities, social sciences, natural sciences and other courses. After accepting a wide range of learning, students choose a professional direction for further study according to their own interests. The aim of undergraduate education of US's universities is the cultivation of students' independent thinking and analysis ability, so that it can grow into a healthy person with rational thinking ability and critical spirit, so as to adapt to the changing world.

China: The undergraduate education in our country emphasizes on the cultivation of "professional talents", which is aimed at the career requirements. The humanities, social sciences are neglected by undergraduate education. There is no obvious difference between the undergraduate education and the vocational education, and students' autonomous learning ability has not been cultivated and improved, so can't adapt to the changing world. Besides this, the technology in engineering field changes quickly, which easily caused a knowledge gap between university and enterprise [1-2].

\subsection{Training Plan and Curriculum System.}

\section{(1) Training plan}

U.S: For the first grade and the second grade undergraduate student, they mainly carry on the study of general education, regardless of majors or departments. After the end of the third semester, they can choose their major and minor specialty according to their own interest, then assigned to the corresponding department or school. In Princeton University, the undergraduate student began to study the professional courses after the fifth semester. In their training plan, the proportion of compulsory courses are relatively small, students have a lot of autonomy to study other courses, as long as the requirements of each module can be satisfied. Besides this, the mutual recognition of the credits intercollegiate channels is opened by many other similar universities, which is beneficial for student to feel different atmosphere of learning, broaden their knowledge and interest.

China: For most of Chinese undergraduate student, the training plans have been identified once they entered the college or university. The training plans are the same for all the students with the same major, and it is difficult to change. Although the students can choose a small number of professional elective courses according to their interests, but the choice is so limited. It is gratifying that more and more universities are aware of the drawbacks of this training plan, they began to attempt the mode of "large class enrollment". The first grade and second grade undergraduate student of several related and similar majors use the same training plan, more comprehensive foundation courses are studied during this period. They will study different professional courses from the beginning of the third grade.

\section{(2) Curriculum system}

In general, the curriculum system of the undergraduate education between American and Chinese universities is similar, which composed of three kind courses, such as general courses, professional basic courses and professional courses, elective courses, etc [3]. However, the proportion of each kind course is quite different. Table 1 and table 2 show the differences between the American and Chinese universities, where Table 1 shows the comparison of the proportion of all kinds of courses, Table 2 shows the comparison of the proportion of practical section courses. The data in two tables are the average value of a number of samples, not for a single sample.

As shown in Table 1 and Table 2, some conclusions can be drawn up, which can be described as follows: 
1) General courses: The proportions of general courses of American universities and Chinese universities are $60 \%$ and $40 \%$, respectively. It shows that American universities pay more attention to the cultivation of general education, not professional skills. Besides this, most of undergraduate student in China spend a lot of time on English study for College English Test (Band 4 or Band 6). Good score can greatly enhance the competitiveness in the job search. They have to give up the study of other general courses, or spend little energy on other general courses.

2) Professional courses: The proportions of professional courses of American universities and Chinese universities are $40 \%$ and $60 \%$, respectively. It shows that Chinese universities pay more attention to the cultivation of professional skills. Meanwhile, the proportion of elective courses in American universities is larger than Chinese universities. It shows that undergraduate student have more autonomy to select their courses.

Table 1 Comparison of the proportion of all kinds of courses between American and Chinese engineering specialty undergraduate (1-1 and 1-2)

\begin{tabular}{cccc}
\hline 1-1 & \multicolumn{3}{c}{ General courses } \\
\hline U.S & Humanities \& social sciences & Natural sciences & Foreign language and sports \\
China & $20 \%$ & $30 \%$ & $10 \%$ \\
\hline \multicolumn{4}{c}{ Professional compulsory courses } \\
\hline $1-2$ & $15 \%$ & Professional compulsory & $10 \%$ \\
\hline U.S & Engineering foundation & $10 \%$ & Selective courses \\
China & $15 \%$ & $30 \%$ & $15 \%$ \\
\hline
\end{tabular}

3) Practical section courses: The proportions of practical section courses of American universities and Chinese universities are similar, but different compositions. American universities pay more attention to the independent curriculum design, while Chinese universities pay more attention to the graduation design. In American universities, there is a strict examination system for independent curriculum design. Research results shows that more than $80 \%$ engineering specialty undergraduate student take part in social practice related to their specialty during their summer vacation [4]. In Chinese universities, it is lack of supervision in the graduation design. There is few undergraduate student spend the summer vacation to participate in social practice related to their specialty.

Table 2 Comparison of the proportion of practical section courses between American and Chinese engineering specialty undergraduate

\begin{tabular}{ccccc}
\hline & Experimental courses & Curriculum design & Graduation design & Social practice \\
\hline U.S & $5 \%$ & $17 \%$ & $3 \%$ & $10 \%$ \\
China & $12 \%$ & $10 \%$ & $8 \%$ & 0 \\
\hline
\end{tabular}

\subsection{Training Quality Evaluation System.}

In this section, the training quality evaluation system will be introduced and analyzed from the aspects of curriculum evaluation system and graduate training quality evaluation system. More details of the curriculum evaluation system can be seen in Table 3 .

Table 3 Comparison of the curriculum evaluation system between American and Chinese engineering specialty undergraduate

\begin{tabular}{cccc}
\hline & Attendance \& homework & Monthly test \& mid-term exam & Final exam \\
\hline U.S & $20 \%$ & $40 \%$ & $40 \%$ \\
China & $10 \%$ & $10-20 \%$ & $70-80 \%$ \\
\hline
\end{tabular}

As shown in Table 3, one can see that American universities pay more attention to the process assessment, rather than a one-time assessment. The proportion of the final exam is lower than $60 \%$. Undergraduate student also pay more attention to the process of learning, rather than the score of final exam [5]. The Chinese universities lack the supervision of the learning process, and teachers can't get real-time feedback from students' learning situation.

The training quality evaluation of university graduates in the American universities is generally completed by the third party institution, the professional matching, income level, job satisfaction, and 
rising space are the key factors to be considered. The evaluation results directly affect the enrollment scale and training plan modification, etc. However, the training quality evaluation of university graduates in Chinese universities mainly depends on the proportion of graduates to obtain a bachelor degree and the proportion of one-time employment. The employment quality of graduates' is ignored, and the evaluation results have no direct influence on the training plan modification. So the training plan of undergraduate student often falls behind the social changes and requirements. The graduates' ability to adapt to society is not enough.

\section{Some Operable Proposals}

To overcome the existing problems of the training mode of engineering specialty undergraduate student in China, the following suggestions are given:

(1) Explore the effective mode of "large class enrollment", distinguish the major should be as late as possible (The time node is best at the beginning of fifth semester);

(2) Revised the training plan of engineering specialty undergraduate student, adjust the proportion allocation of different kind courses, and give more autonomy to students;

(3) Reform the existing training quality evaluation system, introduce the third party institutions to evaluate the training quality of graduates, and form a good feedback mechanism;

(4) Control the enrollment expansion scale of undergraduate student, and increase the input of undergraduate education.

\section{Conclusion}

After more than 10 years enrollment expansion of undergraduate student, the number of undergraduate student in China has been ranked the forefront of the world. However, the training quality did not increase year by year, and many contradictions have become increasingly prominent. By comparing the training mode of engineering specialty undergraduate student between American and Chinese universities, it is found that there are significant differences between two countries in the educational philosophy and training mode, and the relevant suggestions are also discussed. To explore a suitable training system for Chinese engineering specialty undergraduate student, more exploration and practice are needed in the future.

\section{References}

[1] Fang N, Zhao X. A comparative study of learning style preferences between American and Chinese undergraduate engineering students. 2013 IEEE Frontiers in Educatuin Conference. Oklahoma City (USA), Oct.23-Oct.26, p.1704-1705.

[2] Jin YR, Zhang XR. Innovation and entrepreneurship education reform of business administration major: A Chinese case study. Education Journal. Vol. 5 (2016) No. 2, p.27-32.

[3] Liu WH. Comparative research on the undergraduate program for specialty in materials engineering. Advanced Materials Research. Vol. 622-623 (2012) No. 1, p.1873-1876.

[4] López Soblechero MV, González GC, Hernández Ramírez JJ. A comparative study of classroom and online distance modes of official vocational education and training. Plos One. Vol. 9 (2014) No.5, p.1-9.

[5] Malmskold L, Ortengren R, Carlson BE, et al. Instructor based training versus computer based training-a comparative study. Journal of Educational Technology Systems. Vol. 35 (2007) No.4, p.457-478. 